\title{
THE RELEVANCE OF ENVIRONMENTAL CONDITIONS FOR DEPARTURE DECISION CHANGES EN ROUTE IN MIGRATING GEESE
}

\author{
Silke Bauer, ${ }^{1,4}$ Phillip Gienapp, ${ }^{2}$ And Jesper Madsen ${ }^{3}$ \\ ${ }^{1}$ Centre for Limnology, Netherlands Institute of Ecology (NIOO-KNAW), P.O. Box 1299, 3600 BG Maarssen, The Netherlands \\ ${ }^{2}$ Bird Ecology Unit, Department of Biological and Environmental Sciences, University of Helsinki, P.O. Box 65, \\ 00014 Helsinki, Finland \\ ${ }^{3}$ National Environmental Research Institute, Department of Arctic Environment, University of Aarhus, Frederiksborgvej 399, \\ P.O. Box 358, 4000 Roskilde, Denmark
}

\begin{abstract}
The timing of life-cycle events crucially influences fitness, particularly in migratory birds, which visit chains of sites with varying seasonality. Here, we used a proportional hazards model to identify local environmental factors, which a long-distance migrant, the Pink-footed Goose (Anser brachyrhynchus), uses for departure decisions on multiple sites along its spring flyway from Denmark via Norway to Svalbard. Our results not only identified day length, local accumulated temperature, and their interaction as likely candidates, but also (more importantly) showed for the first time that their relevance changes en route.

The results suggest that the birds switch on a "migratory program" in their wintering grounds, with day length providing general information on time of the year and integrated temperatures providing information on larger scale climate trends. Thereafter, on the stopover sites, local accumulated temperatures allow the geese to infer information on the advancement of spring, which is then used to adjust the speed of progressing northward.
\end{abstract}

Key words: Anser brachyrhynchus; local accumulated temperatures; phenotypic plasticity; photoperiod; Pink-footed Goose; proportional hazards model; spring migration.

\section{INTRODUCTION}

In seasonal environments, the timing of activities crucially influence an organism's fitness. Thus, we would expect natural selection to favor individuals that can synchronize energy-demanding processes with peak availability of resources. This particularly applies to migratory birds as they use chains of sites during their annual cycle that often differ in seasonality. Growth and reproduction in particular are restricted to short time frames of favorable conditions within the year. For instance, a number of studies have already shown that, in particular, arctic breeders need to arrive in a (very) narrow time window to make breeding a successful endeavor. Arrival outside this window leads to severe reductions in reproductive success or even complete breeding failure (e.g., Alerstam and Lindström 1990, Prop et al. 2003, Bety et al. 2004, Madsen et al. 2007). On one hand, arriving too early can be costly when environmental conditions are still adverse (e.g., Brown and Brown 2000), and on the other hand, late arriving individuals may suffer from enhanced competition for mates and high-quality territories, loss of body reserves built up in prelude to breeding, and the time constraint to raise young to fledging.

Manuscript received 6 July 2007; revised 13 November 2007; accepted 16 November 2007. Corresponding Editor: W. D. Koenig.

${ }^{4}$ E-mail: s.bauer@nioo.knaw.nl
Timely arrival on the breeding grounds, however, requires "correct" performance in the preceding weeks and months. Migration has to commence at the right time and (northward) advancement should be tuned to seasonal development of food en route ("green-wave hypothesis" as coined for herbivores; Drent et al. 1978, van der Graaf et al. 2006). The latter, in particular, has been proposed as the determinant of overall migration speed, as birds typically spend much longer time on stopover sites to replenish reserves than in actual flight episodes (e.g., Nolet 2006). Thus, birds should be assumed to respond proximately to external factors, such as photoperiod, weather, or food, so as to anticipate the most favorable arrival time in the breeding grounds, but also the periods with the most favorable conditions on the stopover sites during migration.

However, recent climatic alterations may have caused such well-developed adjustments to be out of sync, and thus, resulted in significant consequences on individual fitness and population demographic parameters. There is already ample evidence that phenological patterns of many species including (migratory) birds have been especially responsive to climate warming (e.g., Parmesan and Yohe 2003, Root et al. 2003), and many species have advanced their vernal activities over the past decades (Walther et al. 2002), e.g., by advancing egg laying with earlier onsets of spring (e.g., Sanz 2002, Both et al. 2004, 2005). However, it is often unclear whether such phenological changes coincide with phenological 


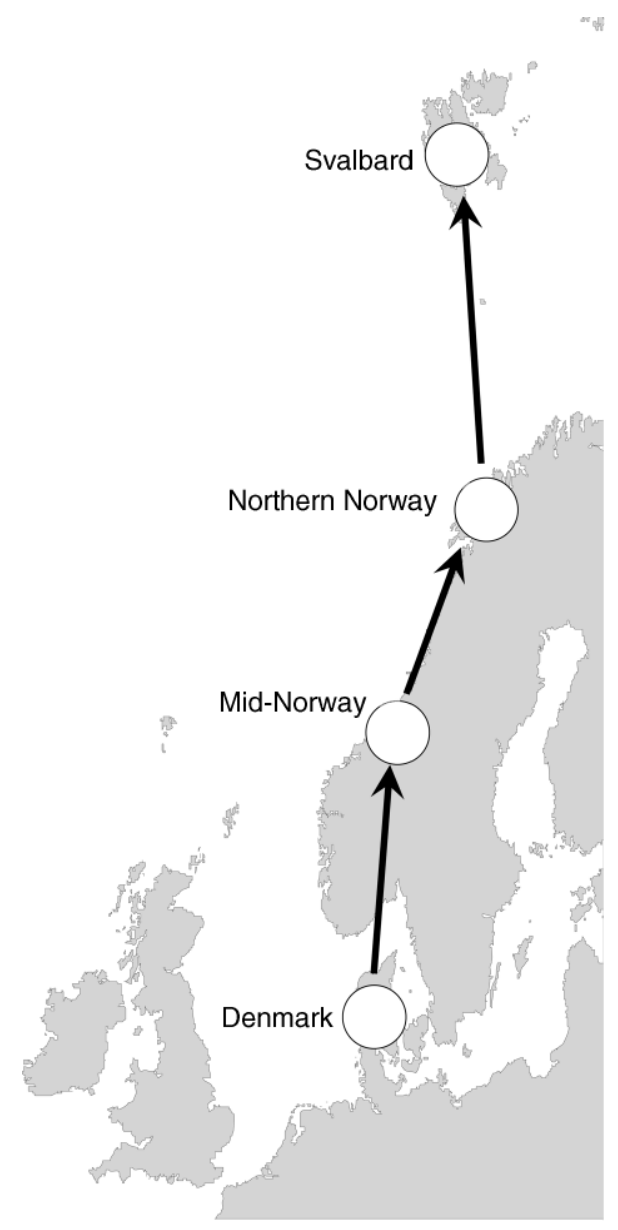

FIG. 1. Pink-footed Geese (Anser brachyrhynchus) migrate in spring from Denmark via two Norwegian stopover sites to their breeding grounds in Svalbard.

changes in the considered species' food abundance (reviewed in Visser and Both 2005) and to which factors individuals actually react in order to schedule their activities.

Therefore, an accurate understanding of the interaction between environmental variables and individual reactions is crucial in predicting the consequences of future climatic changes on individuals and populations. Most attempts at describing phenologies have used a correlative approach between averages of climatic variables measured over a fixed period and the phenological event, e.g., mean egg-laying or mean departure date. Such procedures have a number of drawbacks. First, calculating averages over a number of periods and finding which period explains most variance is a statistically unsatisfying approach. Second, proper choice of the relevant climatic parameters has to be inferred from a large number of possibilities, where a multitude of combinations are also possible. For example, it has frequently been shown that local temperatures are important for timing of breeding in birds (McCleery and Perrins 1998, Meijer et al. 1999, Both et al. 2004, Brommer et al. 2005), but day length can also play a role (Lambrechts and Perret 2000). Ideally, therefore, several variables need to be explored simultaneously. Third, an average of a climatic variable is unlikely to be a correct approximation of the relevant factor that a given individual is responding to. For example, if the average temperature is measured over a fixed period describing the entire spring migration period many individuals will have migrated before the end of this period, and alas, the temperatures after the birds have actually departed are included in the calculation of the "predictive average." Fourth, averages as a proxy of climate are flawed in case one wants to construct a predictive model because the relationship between the average and the true (unknown) proximate factor(s) does not necessarily remain when the climate is changing. For example, an average of a climatic variable over a certain time period does not fully capture changes in spring temperatures that occur only in part of the chosen time interval, and tells little about changes in temperature before the interval chosen. Such changes may, however, be important considerations for the organism.

Analyzing individual observations rather than annual means and including all climatic data up until the event can help to solve the problems inherent to the standard methods to phenology description. The proportional hazards model (Cox 1972) allows exactly this since it is based on individual observations as data points and can handle time-dependent covariates. This model was originally developed for medical survival analysis, but has been applied to biological questions, e.g., foraging behavior in parasitoids (reviewed in Wajnberg 2006) or timing of egg laying in birds (Gienapp et al. 2005). While individual properties such as age or condition can be included as fixed variables, temperature or day length (and even their interactions) can be included as timedependent variables. These time-dependent variables are the key advantage of this model because they provide a way to circumvent the problems described in the previous paragraph.

We employed such a proportional hazards model using individual responses to the values of a set of (environmental) variables to improve our understanding of the spring migration phenology and its driving forces in a long-distance, Arctic-breeding migrant: the Pinkfooted Goose Anser brachyrhynchus. This species winters in Belgium, The Netherlands, and Denmark and commences spring migration in late March/early April. Individuals then travel via two sites in mid-Norway and northern Norway to the breeding grounds on Svalbard, where they arrive in late May/early June (Fig. 1). In particular, we aimed to (1) describe the migration phenology of Pink-footed Geese, (2) identify the predominant factors determining individual departure decisions along the flyway, (3) detect possible differences between sites, and (4) detect changes over time. 


\section{Methods}

Source goose data

Between the years 1990 and 2004, 2100 Pink-footed Geese were captured, aged (into first-winter and older birds, respectively) and individually marked with plastic neck rings during March-April in West Jutland, Denmark (data available online). ${ }^{5}$ Throughout the study period, an intensive resighting program by trained observers was carried out in the spring staging areas. We used resighting data from the three main sites Denmark, mid-Norway, and northern Norway to estimate departure dates of individual geese from each of these sites. Therefore, we considered the last day within a year at which a bird was seen on a particular site as departure date. To prevent the inclusion of false band readings and to determine "true" departure dates, we introduced the following criteria to confirm individual departure dates: For Denmark, birds were included in the analyses if they were resighted in the same year in mid-Norway at most 20 days after the presumed departure from Denmark or in northern Norway at most 40 days after their presumed departure from Denmark. Whereas both Norwegian staging areas are more-or-less well confined, the wintering area is less well confined. Hence, very early departure dates stem most likely from individuals moving to other areas along the Wadden sea coast. By using these thresholds, we removed these observations, which otherwise could create an extremely long left tail in the distribution of departure dates without being too restrictive. A similar criterion was used for departure dates from midNorway: Only departure dates of birds that were resighted in northern Norway at most 20 days after departure from mid-Norway were included. Since northern Norway is the last staging area before the nonstop flight to the breeding grounds, no resightings can be used to "validate" observed departure dates, and we, therefore, included all observations (for resulting sample sizes of all sites, see Appendix A: Table A1). The departure date distribution from northern Norway, however, does not show the long left tail as in Denmark, and thus, no or very few false departure dates are included in this data set. Re-running the analyses for Denmark and mid-Norway using different thresholds did not alter the results substantially (results not shown). Hence, our data selection should not lead to biased results. Furthermore, a study using satellite radiotracking yielded departure and staging times similar to those derived from "conventional" resightings (Glahder et al. 2006).

\section{The proportional hazards model}

The time until a goose departs from its staging ground can be viewed as a "time to event" and can thus be analyzed with survival analysis (Kleinbaum 2005). The proportional hazards model (Cox 1972) describes the probability per unit of time that an event occurs as a function of the baseline hazard, and a set of variables that can include fixed and time-dependent variables. The model is nonparametric in the sense that no assumptions about the distributions of the times to event or the baseline hazard are made. Using a partial maximum likelihood method allows us to estimate the regression coefficients for the different (fixed and time-dependent) variables without specifying the baseline hazard function (Kalbfleisch and Prentice 2002, Prentice and Kalbfleisch 2003). For example, a model for departure dates including only age $(A)$ as a two-level factor ( 0 as first year, 1 as older), temperature $(T)$, and day length $(D)$ as time-dependent variables would be specified as follows:

$$
\begin{aligned}
h(t, A, T, D)= & h_{0}(t) \\
& \times \exp \left(\beta_{A} \times A+\beta_{T} \times T(t)+\beta_{D} \times D(t)\right)
\end{aligned}
$$

where $h(t, A, T, D)$ is the hazard at time $t$ (in days), $h_{0}(t)$ the baseline hazard at $t, T(t)$ the temperature value at $t$, $D(t)$ day length at $t$, and $\beta_{A}, \beta_{T}$, and $\beta_{D}$ the coefficients for age, temperature, and day length, respectively. A positive value of, e.g., $\beta_{A}$ means that the hazard for older individuals is higher, i.e., they depart earlier than firstyear birds. In the same way, a positive value of $\beta_{T}$ means that warmer temperatures increase the hazard and, consequently, individuals will depart earlier. The timedependent variables $T$ and $D$ do not have to be included with their daily measured values but can, for instance, be the average over the last month or the change over the last 10 days, whatever describes the observed values best. A biologically intuitive way to measure such timedependent variables is a "linear predictor" (Bush and Mosteller 1955), which exponentially discounts earlier temperatures (cf. Gienapp et al. 2005):

$$
\lambda(t)=T(t) \times \alpha+\lambda(t-1) \times \alpha
$$

where $\lambda$ is the linear predictor (here used to describe local temperature), $T(t)$ is the daily mean temperature, and $\alpha$ is the weighting factor indicating how important current temperatures are relative to previous ones (Bush and Mosteller 1955). A small $\alpha$ means that the most recent temperatures are relatively unimportant, while a large $\alpha$ places a high weight on the most recent temperature. Thus, $\lambda$ could be interpreted as a "memory variable," and $\alpha$ as an inverse of "memory length."

For each site, we used $\lambda$, calculated from local temperatures, day length, and age of the individual, as variables to explain departure dates. Local temperatures for Denmark (meteorological station Vestervig, $8^{\circ} 19^{\prime} \mathrm{E}$, $\left.56^{\circ} 46^{\prime} \mathrm{N}\right)$ were derived from the European Climate Assessment and Dataset (ECA\&D) (Klein Tank et al. 2002; data and metadata available online), ${ }^{6}$ while local

${ }^{6}\langle$ http://eca.knmi.nl $\rangle$ 

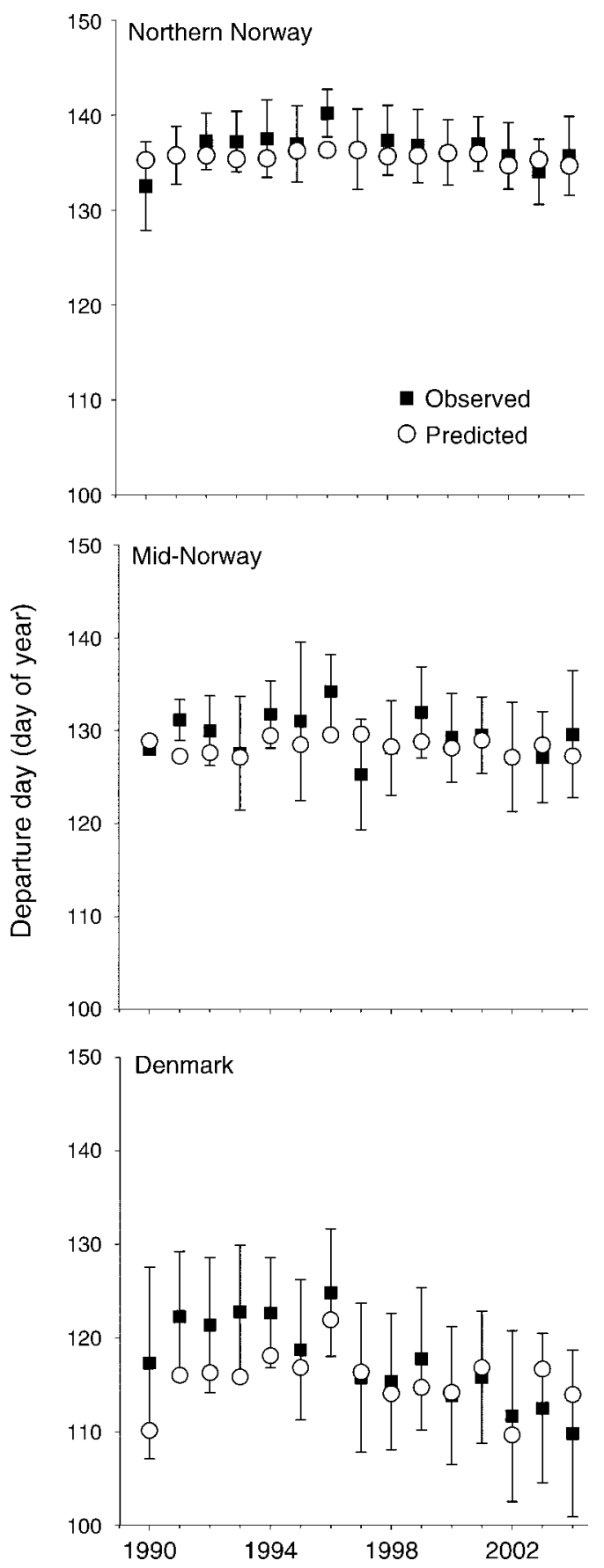

FIG. 2. Pink-footed Geese start migrating from Denmark between mid and late April, stay $\sim 20$ days on the midNorwegian stopover site until late April/early May, and leave thereafter to the northern Norwegian staging site, where they stay until mid/end of May. The three panels show observed (solid symbols) and predicted (open symbols) departure dates (mean $\pm \mathrm{SD}$, where day 1 is 1 January), for Denmark, midNorway, and northern Norway, from 1990 to 2004. For calculating predicted departure dates, the best models and empirically observed proportions of young in the population were used (Madsen et al. 2007; J. Madsen, unpublished data). daily temperatures for the Norwegian sites (from the meteorological station Snåsa $\left[12^{\circ} 28^{\prime} \mathrm{E}, 64^{\circ} 10^{\prime} \mathrm{N}\right]$ for mid-Norway, and from Sortland $\left[15^{\circ} 25^{\prime} \mathrm{E}, 68^{\circ} 42^{\prime} \mathrm{N}\right]$ for northern Norway) were obtained from the Norwegian Meteorological Institute (data available online). ${ }^{7}$ Day lengths for each location were obtained from the U.S. Naval Observatory website (data available online). ${ }^{8}$

Since several individuals were included more than once in our data set and all individuals in a given year experience the same environmental conditions, we fitted a "marginal" proportional hazards model (Therneau and Grambsch 2000) including individual and year as grouping factors to account for this nonindependence of data points.

To identify the optimal model, we ran a series of models for $\lambda$ based on different $\alpha$ 's, day length, and their interaction. The values of $\alpha$ ranged from 0.01 to 0.2 , with increments of 0.01 , except in the case where the best model was based on the lower limit value for $\alpha$, where we additionally tested $\alpha$ 's in the range from 0.001 to 0.09 using increments of 0.001 .

On finding the best model, the effect of age was tested. Overall model fit was judged from Wald statistics, and the significance of a single explanatory variable was judged from $z$ scores calculated using the "robust SE," since these statistics take the nonindependence of "grouped" data points into account (Therneau and Grambsch 2000). All analyses were conducted with $\mathrm{R}$ 2.4.1 (R Development Core Team 2006).

\section{RESUlts}

In general, our model predictions showed good agreement with the observed mean departure dates (Fig. 2). For departures from Denmark, a model including $\lambda$ 's based on $\alpha=0.03$, day length, and their interaction (all significant), produced the best model out of all $\alpha$ 's tested (Fig. 3, Table 1). The subsequent inclusion of age was also significant. The coefficients indicate that warmer temperatures and longer days increased the probability of departure. In addition, the effect of temperature depended on day length such that temperatures later in the year are of greater influence, and thus, lower temperatures suffice to let the birds commence migration in the advanced season. Furthermore, younger birds had a lower probability to leave than older birds, given the same temperature and day length.

For mid-Norway, the best model included $\lambda$ based on $\alpha=0.01$ and age (Fig. 3, Table 1). Day length and the interaction between it and $\lambda$ were nonsignificant $(P=$ 0.35 and $P=0.33$, respectively). Thus, as in Denmark, birds departed earlier from mid-Norway when it is warmer. However, the birds "integrate" this information over a longer period than in Denmark. Younger birds again departed later, on average.

\footnotetext{
7 〈www.met.no $\rangle$

8 http://aa.usno.navy.mil//
} 

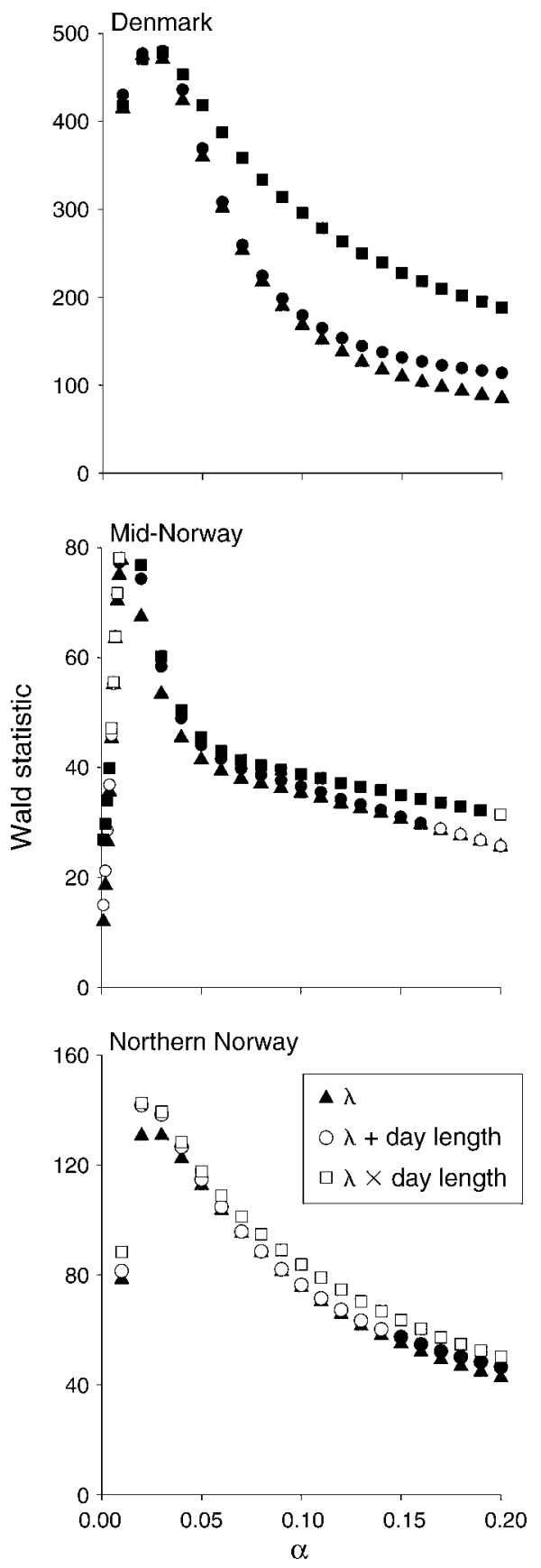

FIG. 3. Model likelihoods (Wald statistics; see Methods for statistical details) for all models in relation to $\alpha$ (weighting factor indicating how important current temperatures are relative to previous ones) on which $\lambda$ (local accumulated temperatures) were based for Denmark, mid-Norway, and northern Norway. Models included either $\lambda, \lambda$ and day length, or their interaction. Solid symbols indicate that all variables were significant $(P<0.05)$, while open symbols indicate that at least one variable was not significant.

The best model for northern Norway included $\lambda$ based on $\alpha=0.03$. Neither day length nor the interaction between day length and $\lambda$ was significant (Fig. 3, Table 1). Thus, the birds departed from northern Norway earlier when it is warmer and the birds integrate temperatures over a period of the same length as in Denmark. Again, age had a significant effect, with younger birds departing later on average than older birds.

\section{Discussion}

We aimed to describe the migration phenology of Pink-footed Geese and, in particular, we sought to identify environmental factors on which individual birds might base their departure decisions. We found significant effects of day length and local accumulated temperatures, indicating that birds are most likely to depart when days are long ( $\sim 15$ hours in Denmark, $\sim 18$ hours in mid-Norway, and $\sim 21$ hours in northern Norway), and it has been warm (on average, $6.3^{\circ} \mathrm{C}$ in Denmark, $5.9^{\circ} \mathrm{C}$ in mid-Norway, and $4.3^{\circ} \mathrm{C}$ in northern Norway) for the previous month. Furthermore, the effect of temperature was affected by day length such that birds become more sensitive to temperature under longer day conditions.

In addition, we tested age as a bird-specific variable for its potential impact on departure decisions. Consistently, we found that age was of approximately equal importance on all sites: young birds depart later than older individuals. This finding is in agreement with earlier observations of younger or less-experienced birds departing later in comparison to the most experienced individuals, which are the first to arrive at a site (Hake et al. 2003, Saino et al. 2004, Lee et al. 2007, Mitrus 2007). In migratory birds, this behavior might simply be a consequence of a lower foraging efficiency due to inexperience of younger birds (Daunt et al. 2007). Moreover, young birds are usually the lowest in dominance hierarchies and are therefore often excluded

TABLE 1. Results of best models for Denmark, mid-Norway, and northern Norway with the variables of local accumulated temperatures $(\lambda)$, day length, age of individuals (Pinkfooted Goose, Anser brachyrhynchus), and interaction between $\lambda$ and day length $(\lambda \times$ day length).

\begin{tabular}{lrrr}
\hline \hline Location and variable & Coefficient & Robust SE & \multicolumn{1}{c}{$z$} \\
\hline Denmark & & & \\
$\lambda$ & 1.463 & 0.364 & $4.02^{* * *}$ \\
$\quad$ Day length & 9.806 & 1.401 & $7.00^{* * *}$ \\
Age & -0.330 & 0.055 & $-6.00^{* * *}$ \\
$\lambda \times$ day length & -0.121 & 0.041 & $-2.99^{* *}$ \\
Mid-Norway & & & \\
$\lambda$ & 0.267 & 0.028 & $9.49^{* * *}$ \\
Day length & 1.171 & 1.258 & $0.93 \mathrm{~ns}$ \\
Age & -0.425 & 0.110 & $-3.86^{* * *}$ \\
$\lambda \times$ day length & -0.083 & 0.085 & $-0.98 \mathrm{~ns}$ \\
Northern Norway & & & \\
$\lambda$ & 0.156 & 0.013 & $11.67^{* * *}$ \\
$\quad$ Day length & 0.283 & 0.308 & $0.92 \mathrm{~ns}$ \\
Age & -0.343 & 0.069 & $-4.92^{* * *}$ \\
$\lambda \times$ day length & -0.022 & 0.019 & $-1.11 \mathrm{~ns}$ \\
\hline
\end{tabular}

Note: Significance levels for the Wald statistic $z$ (see Methods for statistical details) are indicated as follows: $* P<0.05 ; * * P$ $<0.01$; *** $P<0.001$; ns, nonsignificant. 
TABle 2. Correlations between sites in mean daily temperatures over the months April and May 1990-2004 (Pearson correlation coefficient, all $P<0.001)$.

\begin{tabular}{lccc}
\hline \hline \multicolumn{1}{c}{ Site } & Mid-Norway & Northern Norway & Svalbard \\
\hline Denmark & 0.69 & 0.55 & 0.36 \\
Mid-Norway & & 0.76 & 0.44 \\
Northern Norway & & & 0.60 \\
\hline
\end{tabular}

Note: Local temperatures for Svalbard (meteorological station at the Svalbard airport; $78^{\circ} 15^{\prime} 00^{\prime \prime} \mathrm{N}, 15^{\circ} 28^{\prime} 00^{\prime \prime} \mathrm{E}$ ) were also derived from the European Climate Assessment and Dataset (ECA\&D; Klein Tank et al. 2002).

from good foraging sites (Stahl et al. 2001). As a consequence of either or both of these processes, young individuals will have lower fuelling rates, and thus, achieve departure fuel stores later (Heise and Moore 2003). Alternatively, young birds might behave in a riskadverse fashion (Schaub and Jenni 2001, Bayly 2006), and therefore, either leave wintering and stopover sites with extra fuel stores or have higher threshold values. It should be noted that in Pink-footed Geese, families disassociate in late winter, with very few instances of families traveling together on spring migration recorded (J. Madsen, unpublished data). Another explanation for the different behavior of young birds is that they only migrate to test the breeding grounds rather than actually striving to breed. Therefore, they might be less time constrained as there is no pressure on them for timely arrival.

To our knowledge, this is the first explicit demonstration that the degree to which birds integrate these environmental variables in their departure decisions changes en route: While in Denmark, local accumulated temperature $(\lambda)$, day length, and their interaction significantly explained departure dates; in mid-Norway and in northern Norway, only the temperature term $(\lambda)$ remained explanatory. Moreover, these factors not only changed qualitatively but also quantitatively, e.g., coefficients for $\lambda$ decreased from site to site as the birds move northwards, indicating a reduction in $\lambda$ 's influence on migration scheduling. Thus, birds in Denmark determine when they should initiate migration using day length as a strong, dominant proxy ("zeitgeber") for time of the year. Earlier studies have already characterized the role of photoperiod as "permissive" (Hau and Gwinner 1997), e.g., for initiating migratory restlessness (Gwinner 1996a, Helm and Gwinner 2005), gonadal development (Beebe et al. 2005), or egg laying (Lambrechts et al. 1996). Thus, day length dictates the possible time frame in which a given activity can be successfully performed and within which synchronization with other factors comes into play. The interaction term between both, which our model has shown to be significant only in Denmark, supports this: Temperatures will be more relevant on longer days. Thereafter, in mid-Norway and northern Norway, birds do not react to photoperiod anymore (a phenomenon referred to as photorefractoriness; Beebe et al. 2005) because once migration has commenced, there remains only the need to adjust the speed of northward progression to prevailing climatic conditions. Besides, in the northerly sites, the dark period becomes shorter as the season progresses, disappears eventually completely in the high North, and plays, thus, only a minor role.

This provokes the question: What information can the birds actually infer from these changes in day length and temperatures? The birds cannot foresee the conditions they will encounter at a distant site on departure from the preceding site. However, it would be highly energy inefficient if they would depart only needing to return due to adverse conditions on the following site. Although such behavior has been observed, it has mainly been described in passerines (Richardson 1978, Åkesson 1999, Thorup 2004), its frequency remains obscure, and neckband and satellite transmitter studies of larger birds such as geese and swans suggest that this behavior is an exception rather than the norm: In our well-studied species it has never been observed (e.g., Glahder et al. 2006; J. Madsen, unpublished data). Thus, local environmental factors must reliably inform the birds about the conditions on the destination site. The identified best $\alpha$ 's indicate that the birds "integrate" temperatures over two to three months and, hence, react to general vegetation development (cf. Menzel et al. 2001, Fitter and Fitter 2002). Similar weather conditions in relevant periods indicate similar growth stages of vegetation and, therefore, if climatic variables were correlated over certain distances, they might be used by the geese to predict the approximate food availability on the following stopover site(s). Indeed, April and May temperatures are significantly correlated between the sites (Table 2). However, the degree to which conditions on a future site can be predicted from conditions on the actual site differs with distance: While the Danish conditions can predict temperatures in mid-Norway, the reliability of these predictions lessens for the conditions further north, that is, for northern Norway and even more for Svalbard. Similarly, temperatures in mid-Norway were a good indicator for conditions in northern Norway, but again, less so for Svalbard. Moreover, there was considerable variation in these correlations between years such that, in some years, conditions were only slightly or not correlated (not shown).

What, then, are the implications of our findings with regard to projected climatic changes? Climate change may alter the correlation between climatic variables in the wintering and breeding areas as temperature trends differ between regions (Luterbacher et al. 2004). Consequently, species or populations wintering closer to their breeding areas and/or staging for longer or more often during migration should be better able to adjust to climate change. Although long-distance migrants wintering south of the Sahara are thought to rely mainly on internal rhythms and photoperiod to schedule their migration (Berthold 1996, Gwinner 1996b), it has 
recently also been found that environmental conditions in the wintering areas and temperatures en route are important (Ahola et al. 2004, Saino et al. 2004, Hüppop and Winkel 2006). However, whether and how well short- and long-distance migrants can adjust to climate change by phenotypic plasticity will depend on the nature of the relevant factors. The environmental factors affecting migratory timing in Pink-footed Geese identified here include local accumulated temperatures (susceptible to climate change) and day length (not affected by any change to the climatic regime). This means that the relationship between photoperiod and general advancement of spring, on which the geese are reliant for successful timing of their departure from wintering and staging grounds, is likely to change in the future under ongoing climate change. Consequently, the geese may be leaving too late and arriving too late at the breeding grounds to breed successfully. Coping with this uncoupling of environmental factors (or cues) requires a microevolutionary change of the way in which the geese respond to photoperiod. Genetic variation in the timing of autumn migration in relation to photoperiod has been demonstrated in warblers (Pulido et al. 2001, Pulido and Widmer 2005). Assuming a similar genetic component in geese, the possible microevolutionary change is, however, likely to be too slow to keep up with the rate of climate change (cf. Parmesan 2006, Gienapp et al. 2007, 2008). In contrast to this, the temperature dependency of the timing of migration suggests that the geese can advance their spring migration by phenotypic plasticity, as long as conditions on successive stopover sites remain correlated and temperatures in one place continue to provide reliable proxies on conditions on next site. However, temperature increases induced by climate change have been heterogeneous in time and space (Easterling et al. 1997, Luterbacher et al. 2004) and photoperiod, which is used as a factor to determine departure, will not change. Consequently, the phenotypic plastic response to spring temperature will enable the geese to track changes in their environment to some extent. It is however, unclear whether this response will be sufficient since photoperiod will not change and an evolutionary change in phenotypic plasticity is probably too slow. A resulting mismatch between arrival time at the breeding grounds and quality and quantity of the geese's food supply could reduce their reproductive success with consequences at the population level in the long term.

\section{ACKNowledgments}

We are grateful to M. Klaassen, S. Hahn, B. Hoye, and two anonymous referees for comments on earlier versions of this manuscript, and to I. Tombre for providing temperature data for the Norwegian sites. This is publication 4212 of the Netherlands Institute of Ecology (NIOO-KNAW).

\section{Literature Cited}

Ahola, M., T. Laaksonen, K. Sippola, T. Eeva, K. Rainio, and E. Lehikoinen. 2004. Variation in climate warming along the migration route uncouples arrival and breeding dates. Global Change Biology 10:1610-1617.

Åkesson, S. 1999. Do passerine migrants captured at an inland site perform temporary reverse migration in autumn? Ardea 87:129-137.

Alerstam, T., and Å. Lindström. 1990. Optimal bird migration: the relative omportance of time, energy, and safety. Pages 331-351 in E. Gwinner, editor. Bird migration. SpringerVerlag, Berlin, Germany.

Bayly, N. J. 2006. Optimality in avian migratory fuelling behaviour: a study of a trans-Saharan migrant. Animal Behaviour 71:173-182.

Beebe, K., G. E. Bentley, and M. Hau. 2005. A seasonally breeding tropical bird lacks absolute photorefractoriness in the wild, despite high photoperiodic sensitivity. Functional Ecology 19:505-512.

Berthold, P. 1996. Control of bird migration. Chapman and Hall, London, UK.

Bety, J., J. F. Giroux, and G. Gauthier. 2004. Individual variation in timing of migration: causes and reproductive consequences in greater snow geese (Anser caerulescens atlanticus). Behavioural Ecology and Sociobiology 57:1-8.

Both, C., et al. 2004. Large-scale geographical variation confirms that climate change causes birds to lay earlier. Proceedings of the Royal Society B 271:1657-1662.

Both, C., R. G. Bijlsma, and M. E. Visser. 2005. Climatic effects on timing of spring migration and breeding in a long-distance migrant, the pied flycatcher Ficedula hypoleuca. Journal of Avian Biology 36:368-373.

Brommer, J. E., J. Merila, B. C. Sheldon, and L. Gustafsson. 2005. Natural selection and genetic variation for reproductive reaction norms in a wild bird population. Evolution 59:13621371.

Brown, C. R., and M. B. Brown. 2000. Weather-mediated natural selection on arrival time in cliff swallows (Petrochelidon pyrrhonota). Behavioral Ecology and Sociobiology 47: 339-345.

Bush, R. R., and F. Mosteller. 1955. Stochastic models for learning. Wiley, New York, New York, USA.

Cox, D. R. 1972. Regression models and life tables. Biometrics 39:67-77.

Daunt, F., S. Wanless, M. P. Harris, L. Money, and P. Monaghan. 2007. Older and wiser: improvements in breeding success are linked to better foraging performance in European shags. Functional Ecology 21:561-567.

Drent, R., B. Ebbinge, and B. Weijand. 1978. Balancing the energy budget of arctic-breeding geese throughout the annual cycle; a progress report. Verhandlungen der ornithologischen Gesellschaft Bayerns 23:239-264.

Easterling, D. R., B. Horton, P. D. Jones, T. C. Peterson, T. R. Karl, D. E. Parker, M. J. Salinger, V. Razuvayev, N. Plummer, P. Jamason, and C. K. Folland. 1997. Maximum and minimum temperature trends for the globe. Science 277: 364-367.

Fitter, A. H., and R. S. R. Fitter. 2002. Rapid changes in flowering time in British plants. Science 296:1689-1691.

Gienapp, P., L. Hemerik, and M. E. Visser. 2005. A new statistical tool to predict phenology under climate change scenarios. Global Change Biology 11:600-606.

Gienapp, P., R. Leimu, and J. Merila. 2007. Responses to climate change in avian migration time - microevolution or phenotypic plasticity? Climate Research 35:25-35.

Gienapp, P., C. Teplitsky, J. S. Alho, A. M. Mills, and J. Merila. 2008. Climate change and evolution: disentangling environmental and genetic responses. Molecular Ecology 17: 167-178.

Glahder, C. M., A. D. Fox, C. E. Hubner, J. Madsen, and I. M. Tombre. 2006. Pre-nesting site use of satellite transmitter tagged Svalbard Pink-footed Geese Anser brachyrhynchus. Ardea 94:679-690. 
Gwinner, E. 1996a. Circadian and circannual programmes in avian migration. Journal of Experimental Biology 199:39-48.

Gwinner, E. 1996b. Circannual clocks in avian reproduction and migration. Ibis 138:47-63.

Hake, M., N. Kjellen, and T. Alerstam. 2003. Age-dependent migration strategy in honey buzzards Pernis apivorus tracked by satellite. Oikos 103:385-396.

Hau, M., and E. Gwinner. 1997. Adjustment of House Sparrow circadian rhythms to a simultaneously applied light and food zeitgeber. Physiology and Behavior 62:973-981.

Heise, C. D., and F. R. Moore. 2003. Age-related differences in foraging efficiency, molt, and fat deposition of Gray Catbirds prior to autumn migration. Condor 105:496-504.

Helm, B., and E. Gwinner. 2005. Carry-over effects of day length during spring migration. Journal of Ornithology 146: $348-354$.

Hüppop, O., and W. Winkel. 2006. Climate change and timing of spring migration in the long-distance migrant Ficedula hypoleuca in central Europe: the role of spatially different temperature changes along migration routes. Journal of Ornithology 147:344-353.

Kalbfleisch, J. D., and R. L. Prentice. 2002. The statistical analysis of failure time data. Wiley Series in Probability and Statistics, Hoboken, New Jersey, USA.

Kleinbaum, D. G. 2005. Survival analysis: a self-learning text. Springer-Verlag, Berlin, Germany.

Klein Tank, A. M. G., et al. 2002. Daily dataset of 20th-century surface air temperature and precipitation series for the European Climate Assessment. International Journal of Climatology 22:1441-1453.

Lambrechts, M. M., and P. Perret. 2000. A long photoperiod overrides non-photoperiodic factors in blue tits' timing of reproduction. Proceedings of the Royal Society B 267:585588.

Lambrechts, M. M., P. Perret, and J. Blondel. 1996. Adaptive differences in the timing of egg laying between different populations of birds result from variation in photoresponsiveness. Proceedings of the Royal Society B 263:19-22.

Lee, D. E., J. M. Black, J. E. Moore, and J. S. Sedinger. 2007. Age-specific stopover ecology of Black Brant at Humboldt Bay, California. Wilson Journal of Ornithology 119:9-22.

Luterbacher, J., D. Dietrich, E. Xoplaki, M. Grosjean, and H. Wanner. 2004. European seasonal and annual temperature variability, trends, and extremes since 1500 . Science 303: 1499-1503.

Madsen, J., M. Tamstorf, M. Klaassen, N. Eide, C. Glahder, F. Riget, H. Nyegaard, and F. Cottaar. 2007. Effects of snow cover on the timing and success of reproduction in highArctic pink-footed geese Anser brachyrhynchus. Polar Biology 30:1363-1372.

McCleery, R. H., and C. M. Perrins. 1998. ... temperature and egg-laying trends. Nature 391:30-31.

Meijer, T., U. Nienaber, U. Langer, and F. Trillmich. 1999. Temperature and timing of egg-laying of European Starlings. Condor 101:124-132.

Menzel, A., N. Estrella, and P. Fabian. 2001. Spatial and temporal variability of the phenological seasons in Germany from 1951 to 1996. Global Change Biology 7:657-666.

Mitrus, C. 2007. Is the later arrival of young male red-breasted flycatchers (Ficedula parva) related to their physical condition? Journal of Ornithology 148:53-58.

Nolet, B. A. 2006. Speed of spring migration of Tundra Swans Cygnus columbianus in accordance with income or capital breeding strategy? Ardea 94:579-591.
Parmesan, C. 2006. Ecological and evolutionary responses to recent climate change. Annual Review of Ecology Evolution and Systematics 37:637-669.

Parmesan, C., and G. Yohe. 2003. A globally coherent fingerprint of climate change impacts across natural systems. Nature 421:37-42.

Prentice, R. L., and J. D. Kalbfleisch. 2003. Mixed discrete and continuous cox regression model. Lifetime Data Analysis 9: 195-210.

Prop, J., J. M. Black, and P. Shimmings. 2003. Travel schedules to the high arctic: barnacle geese trade-off the timing of migration with accumulation of fat deposits. Oikos 103:403414.

Pulido, F., P. Berthold, G. Mohr, and U. Querner. 2001. Heritability of the timing of autumn migration in a natural bird population. Proceedings of the Royal Society of London B 268:953-959.

Pulido, F., and M. Widmer. 2005. Are long-distance migrants constrained in their evolutionary response to environmental change? Causes of variation in the timing of autumn migration in a Blackcap (S. atricapilla) and two Garden Warbler (Sylvia borin) populations. Annals of the New York Academy of Sciences 1046:228-241.

R Development Core Team. 2006. R: A language and environment for statistical computing. R Foundation for Statistical Computing, Vienna, Austria.

Richardson, W. J. 1978. Timing and amount of bird migration in relation to weather: a review. Oikos 30:224-272.

Root, T. L., J. T. Price, K. R. Hall, S. H. Schneider, C. Rosenzweig, and J. A. Pounds. 2003. Fingerprints of global warming on wild animals and plants. Nature 421:57-60.

Saino, N., T. Szep, M. Romano, D. Rubolini, F. Spina, and A. P. Moller. 2004. Ecological conditions during winter predict arrival date at the breeding quarters in a transSaharan migratory bird. Ecology Letters 7:21-25.

Sanz, J. J. 2002. Climate change and breeding parameters of great and blue tits throughout the western Palaearctic. Global Change Biology 8:409-422.

Schaub, M., and L. Jenni. 2001. Variation of fuelling rates among sites, days and individuals in migrating passerine birds. Functional Ecology 15:584-594.

Stahl, J., P. H. Tolsma, M. J. J. E. Loonen, and R. H. Drent. 2001. Subordinates explore but dominants profit: resource competition in high Arctic barnacle goose flocks. Animal Behaviour 61:257-264.

Therneau, T. M., and P. M. Grambsch. 2000. Modeling survival data: extending the Cox Model. Springer-Verlag, Berlin, Germany.

Thorup, K. 2004. Reverse migration as a cause of vagrancy. Bird Study 51:228-238.

van der Graaf, S., J. Stahl, J. P. Bakker, and R. H. Drent. 2006. Surfing on a green wave: How plant growth drives spring migration in the barnacle goose. Ardea 94:567-577.

Visser, M. E., and C. Both. 2005. Shifts in phenology due to global climate change: the need for a yardstick. Proceedings of the Royal Society B 272:2561-2569.

Wajnberg, E. 2006. Time allocation strategies in insect parasitoids: from ultimate predictions to proximate behavioral mechanisms. Behavioral Ecology and Sociobiology 60: 589-611.

Walther, G. R., E. Post, P. Convey, A. Menzel, C. Parmesan, T. J. C. Beebee, J. M. Fromentin, O. Hoegh-Guldberg, and F. Bairlein. 2002. Ecological responses to recent climate change. Nature 416:389-395.

\section{APPENDIX}

Sample sizes (no. individuals) for Denmark, mid-Norway, and northern Norway throughout the study period. (Ecological Archives E089-114-A1). 